\title{
Analysis of the Essential Features in the Tasks of Identification
}

\author{
Vadim N. Romanov \\ St.-Petersburg, Russia
}

\begin{abstract}
This paper proposes a new approach to defining the essential features in the task of identification based on the use of topological methods. To extend the scope of analysis and reducing its complexity applies fuzzy representation of the original data. The obtained results show the efficiency of the proposed approach.
\end{abstract}

Keywords: Task of identification; fuzzy gradations; topological analysis; essential features; level of connectivity; eccentricity.

\section{INTRODUCTION}

The problem of identification arises in many scientific and technical applications related to modeling of systems (some applications use the term "recognition"). The main difficulty of its solution is connected with the identification of essential (significant) features (signs, characteristics, indexes, attributes, parameters, criteria) are used to describe the object. To determine the relative informativity (importance) of the characteristics the statistical methods as a rule are applied [2] and it is assumed that the objects and the signs are clear (completely) defined, and the model is known. In fact, the incompleteness of knowledge about the subject area, as well as the inconsistency of data obtained by different methods, and measurement errors lead to the ambiguity of describing and relating the characteristics to the objects. To reflect the incompleteness of knowledge about the subject area, as well as to reduce the influence of measurement errors and data inconsistencies about the signs and their correlation objects, we use the representation of signs in the form of fuzzy gradations. Imagine the original data in the form of a matrix of incidence $r_{i k}$ relation $R$ between objects and signs, which takes into account the degree of manifestation of signs. In the matrix $r_{i k}$, the first index corresponds to the objects and the other - characteristics, $i=1, \ldots, n ; k=$ $1, \ldots, m$. The values $r_{i k}$ are presented in the form of fuzzy gradations (levels): VL is a very low value, $\mathrm{L}-$ low; $\mathrm{M}$ - medium; $\mathrm{H}$ - high; $\mathrm{VH}$ - is very high. To improve the accuracy of distinction can be used intermediate gradations between the basic. In addition, are assumed known marginal gradations: VVH (highest value) and VVL (lowest value), the first of which means that the feature is always found, and second, that is not found at all. As a measure of the proximity (closeness) of the objects $i$ and $k$ according to criterion $j$ using the value of $\alpha_{i k}$, which takes the following values: $\alpha_{i k}=\mathrm{VH}$ if $r_{i j}=r_{k j} ; \alpha_{i k}=\mathrm{H}$ if $r_{i j}$ and $r_{k j}$ are different by one gradation, etc., $\alpha_{i k}=$ VL if $r_{i j}$ and $r_{k j}$ are distinguished into four gradations. For values of $\alpha_{i k}$ we define the condition of validity in the form [3]

$\alpha_{i k}>\mathrm{H}$

When solving the problem of identification of particular importance are multiple matching characteristics. The application of topological methods allows to investigate the connections due to the relationship between objects and signs and to ascertain the coincidences of signs. Each object or feature in the analysis of connectivity is considered as a simplex and the set of simplexes as complex, which has a multidimensional structure [1]. The decision on the essentiality (importance) of signs shall take into account the connectivity of the signs, the values of their eccentricities and the dimensions of the simplexes and the complex. Consider the determination of significant characteristics for the three cases commonly encountered in practice: 1) objects of one class are characterized by qualitative characteristics; 2) objects of different classes are characterized by quantitative and qualitative characteristics; 3) there are uncertain (unknown) objects that require identification (recognition) on available characteristics.

\section{ANALYSIS OF QUALITATIVE CHARACTERISTICS}

In the first case all features are quality and presented expert evaluation. It is required to determine their significance (informativity) for the identification of objects of certain class. Initial data for this case are presented in table 1 . It is sufficient to use only the gradations VL and VH since according to the ratio of (1) the reliability is ensured for values greater than $\mathrm{H}$. Gradation VL means that the sign is very rare and $\mathrm{VH}$ is very often. 
Table 1 Initial data for the first case

\begin{tabular}{|c|c|c|c|c|c|c|}
\hline \multirow[t]{2}{*}{ Objects } & \multicolumn{5}{|c|}{ Signs } & \multirow{2}{*}{$\begin{array}{c}\text { Sum of values } \\
\text { VH }\end{array}$} \\
\hline & $K_{1}$ & $K_{2}$ & $K_{3}$ & $K_{4}$ & $K_{5}$ & \\
\hline$x_{1}$ & VL & $\mathrm{VH}$ & $\mathrm{VH}$ & $\mathrm{VH}$ & $\mathrm{VH}$ & 4 \\
\hline$x_{2}$ & $\mathrm{VH}$ & VH & VL & VL & $\mathrm{VH}$ & 3 \\
\hline$x_{3}$ & $\mathrm{VH}$ & $\mathrm{VH}$ & $\mathrm{VH}$ & $\mathrm{VH}$ & $\mathrm{VH}$ & 5 \\
\hline$x_{4}$ & VL & VH & VL & VL & $\mathrm{VH}$ & 2 \\
\hline$x_{5}$ & VL & $\mathrm{VH}$ & VL & $\mathrm{VH}$ & $\mathrm{VH}$ & 3 \\
\hline$x_{6}$ & $\mathrm{VH}$ & VL & VL & VL & $\mathrm{VH}$ & 2 \\
\hline Sum of values VH & 3 & 5 & 2 & 3 & 6 & 19 \\
\hline
\end{tabular}

At first we will analyse the connectivity of the set of signs that allows taking into account the
Coincidence (crossing, intersection) of signs of a different order. The results of the analysis are given in table 2.

Table 2 Analysis of characteristics for the first case

\begin{tabular}{|c|c|c|}
\hline Level of connectivity & Number of components & Structure of components \\
\hline$q=5$ & $Q_{5}=1$ & $\left\{K_{5}\right\}$ \\
\hline$q=4$ & $Q_{4}=1$ & $\left\{K_{5}, K_{2}\right\}$ \\
\hline$q=3$ & $Q_{3}=1$ & $\left\{K_{5}, K_{2}\right\}$ \\
\hline$q=2$ & $Q_{2}=1$ & $\left\{K_{5}, K_{2}, K_{4}, K_{1}\right\}$ \\
\hline$q=1$ & $Q_{1}=1$ & $\{$ all $K\}$ \\
\hline$q=0$ & $Q_{0}=1$ & $\{$ all $K\}$ \\
\hline
\end{tabular}

The first structural vector has the form $Q=$

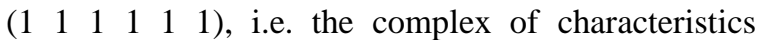
(signs) is strongly connected in all dimensions. This suggests that the complex of signs is entire formation (connected variety). The sign $K_{5}$ is available to all six objects, signs $K_{5}$ and $K_{2}$ are inherent in five objects, etc.; all signs have at least two crossings $(q=1)$. We calculate the eccentricity for each characteristicsimplex from the ratio [3]

$\varepsilon(x)=q_{\max }(x)-q_{0}(x)$,

Where $q_{\max }(x)$ - the maximum level of connectivity of the simplex, $q_{0}(x)$ - the level of connectivity at which the simplex is combined first with any other simplex. Calculations show that the eccentricity for $K_{1}, K_{2}, K_{3}, K_{4}$ equals 0 and for $K_{5}$ equals 1 . Therefore the characteristic $K_{5}$ is the most typical for all objects of the class and stands out among other signs according to the degree of adaptability in the complex. The analysis shows that the most relevant (informative) is the sign of $K_{5}$, and then follow the signs $K_{2}, K_{4}, K_{1}$ and $K_{3}$. The characteristic $K_{3}$ is in last place, as it has only two crossings with other features (signs). The sign $K_{1}$ has three intersections only with $K_{5}$, so inferior to the $K_{4}$, which has three crossings with $K_{2}$ and $K_{5}$. Now, we perform topological analysis of the objects, which allows to judge the adequacy of the description of objects selected features. The results are given in table 3 .

Table 3 Analysis of objects for the first case

\begin{tabular}{|c|c|c|}
\hline Level of connectivity & Number of components & Structure of components \\
\hline$q=4$ & $Q_{4}=1$ & $\left\{x_{3}\right\}$ \\
\hline$q=3$ & $Q_{3}=1$ & $\left\{x_{3}, x_{1}\right\}$ \\
\hline$q=2$ & $Q_{2}=1$ & $\left\{x_{3}, x_{1}, x_{2}, x_{5}\right\}$ \\
\hline$q=1$ & $Q_{1}=1$ & $\{$ all $x\}$ \\
\hline$q=0$ & $Q_{0}=1$ & $\{$ all $x\}$ \\
\hline
\end{tabular}

The first structural vector has the form $Q=$ (1 111111$)$, that shows high connectivity and uniformity of the objects complex. The eccentricity for $x_{1}, x_{2}, x_{4}, x_{5}, x_{6}$ is equal to 0 , and for $x_{3}$ equals 1 , i.e., the object $x_{3}$ is the most typical representative of the class of objects. Results of analysis show that for object identification we can use three signs $K_{5}, K_{2}$ and $K_{4}$ or two $K_{5}$ and $K_{2}$, as these signs all objects are intersected with $x_{3}$. The exception is the object $x_{6}$, for more precise identification of which might take into account the sign $K_{1}$.

\section{ANALYSIS OF QUANTITATIVE AND QUALITATIVE CHARACTERISTICS}

In the second case, to describe the objects are used quantitative and qualitative characteristics. The quantitative characteristics are obtained from measurements and are expressed in physical (named) units. The quality characteristics are determined by the experts and are dimensionless. Set of objects is heterogeneous and consists of two classes $X$ and $Y$. For the joint analysis of data all the characteristics are normalized to the range $(0,1)$ by well-known linear transformation. We use fuzzy gradations, so that the 
interval $(0,0.2)$ corresponds to gradation $\mathrm{VL}$, the interval $(0.2,0.4)$ - gradation $\mathrm{L}$, etc., the interval $(0.8,1)$ - gradation VH. Initial data for this case are presented in table 4 and table 5. For more accuracy we also use along with the basic gradations the intermediate gradations: (VL-L) - between VL and $\mathrm{L}$; (L-M) - between L and M; $(\mathrm{M}-\mathrm{H})$ - between $\mathrm{M}$ and $\mathrm{H}$; $(\mathrm{H}-\mathrm{VH})$ - between $\mathrm{H}$ and $\mathrm{VH}$.

Table 4 Initial data for the second case (objects $\mathrm{x}$ )

\begin{tabular}{|c|c|c|c|c|c|c|}
\hline \multirow{2}{*}{ Objects } & \multicolumn{5}{|c|}{ Signs } & \multirow{2}{*}{$\begin{array}{c}\text { Sum of values more than } \\
\mathrm{H}\end{array}$} \\
\hline & $\overline{K_{1}}$ & $K_{2}$ & $K_{3}$ & $K_{4}$ & $K_{5}$ & \\
\hline$x_{1}$ & VL & $\mathrm{M}$ & $\mathrm{L}$ & $>\mathrm{H}$ & $\mathrm{M}$ & $(1)$ \\
\hline$x_{2}$ & $\mathrm{VH}$ & $\mathrm{L}$ & VL-L & $\mathrm{L}$ & VL & 1 \\
\hline$x_{3}$ & VH & $>\mathrm{H}$ & $\mathrm{L}$ & $\mathrm{L}$ & M & $1+(1)$ \\
\hline$x_{4}$ & VL & VL-L & VL-L & $\mathrm{M}-\mathrm{H}$ & $\mathrm{VH}$ & 1 \\
\hline$x_{5}$ & $\mathrm{VH}$ & M-H & $\mathrm{L}$ & $\mathrm{VH}$ & VL & 2 \\
\hline$x_{6}$ & VL & $\mathrm{VH}$ & $\mathrm{L}$ & $\mathrm{L}$ & $\mathrm{M}$ & 1 \\
\hline$x_{7}$ & VL & $\mathrm{M}$ & L-M & $\mathrm{M}$ & M & 0 \\
\hline$x_{8}$ & $\mathrm{VH}$ & $\mathrm{L}$ & $\mathrm{L}$ & $\mathrm{M}-\mathrm{H}$ & $\mathrm{VL}$ & 1 \\
\hline$x_{9}$ & $\mathrm{VH}$ & $>\mathrm{H}$ & $\mathrm{L}$ & VL & $\mathrm{VH}$ & $2+(1)$ \\
\hline$x_{10}$ & VL & $\mathrm{M}$ & VL-L & L-M & $\mathrm{M}$ & 0 \\
\hline $\begin{array}{l}\text { Sum of values more } \\
\text { than } \mathrm{H} \quad \text { (for } x \text { ) }\end{array}$ & 5 & $1+(2)$ & 0 & $1+(1)$ & 2 & $9+(3)=12$ \\
\hline
\end{tabular}

Table 5 Initial data for the second case (objects y)

\begin{tabular}{|c|c|c|c|c|c|c|}
\hline \multirow{2}{*}{ Objects } & \multicolumn{5}{|c|}{ Signs } & $\begin{array}{c}\text { Sum of values more } \\
\text { than H }\end{array}$ \\
\cline { 2 - 6 } & $K_{1}$ & $K_{2}$ & $K_{3}$ & $K_{4}$ & $K_{5}$ & 1 \\
\hline$y_{1}$ & $\mathrm{VH}$ & $\mathrm{M}$ & $\mathrm{M}$ & $\mathrm{M}$ & $\mathrm{VL}$ & 2 \\
\hline$y_{2}$ & $\mathrm{VH}$ & $\mathrm{M}-\mathrm{H}$ & $<\mathrm{H}$ & $\mathrm{VL}$ & $\mathrm{VH}$ & 1 \\
\hline$y_{3}$ & $\mathrm{VL}$ & $\mathrm{VL}-\mathrm{L}$ & $\mathrm{L}$ & $\mathrm{M}$ & $\mathrm{VH}$ & $2+[1]$ \\
\hline$y_{4}$ & $\mathrm{VL}$ & $>\mathrm{L}$ & $\mathrm{VH}$ & $\mathrm{H}-\mathrm{VH}$ & $\mathrm{VH}$ & 1 \\
\hline$y_{5}$ & $\mathrm{VH}$ & $>\mathrm{VL}$ & $\mathrm{L}$ & $<\mathrm{H}$ & $\mathrm{M}$ & $(1)$ \\
\hline$y_{6}$ & $\mathrm{VL}$ & $<\mathrm{VL}$ & $\mathrm{VL}$ & $>\mathrm{H}$ & $\mathrm{VL}$ & 1 \\
\hline$y_{7}$ & $\mathrm{VH}$ & $\mathrm{L}$ & $\mathrm{VL}-\mathrm{L}$ & $\mathrm{M}$ & $\mathrm{M}$ & $(1)$ \\
\hline$y_{8}$ & $\mathrm{VL}$ & $>\mathrm{M}$ & $\mathrm{L}$ & $>\mathrm{H}$ & $\mathrm{M}$ & 2 \\
\hline$y_{9}$ & $\mathrm{VH}$ & $\mathrm{VL}-\mathrm{L}$ & $>\mathrm{VL}-\mathrm{L}$ & $\mathrm{M}$ & $\mathrm{VH}$ & 1 \\
\hline$y_{10}$ & $\mathrm{VL}$ & $\mathrm{L}$ & $>\mathrm{L}$ & $>\mathrm{L}$ & $\mathrm{VH}$ & $(1)$ \\
\hline$y_{11}$ & $\mathrm{VL}$ & $\mathrm{VL}$ & $>\mathrm{VL}$ & $>\mathrm{H}$ & $\mathrm{VL}$ & 1 \\
\hline$y_{12}$ & $\mathrm{VH}$ & $<\mathrm{L}-\mathrm{M}$ & $\mathrm{L}-\mathrm{M}$ & $<\mathrm{H}$ & $\mathrm{M}$ & $2+(1)$ \\
\hline$y_{13}$ & $\mathrm{VH}$ & $\mathrm{M}-\mathrm{H}$ & $>\mathrm{H}$ & $>\mathrm{M}-\mathrm{H}$ & $\mathrm{VH}$ & 1 \\
\hline$y_{14}$ & $\mathrm{VH}$ & $>\mathrm{M}$ & $>\mathrm{M}$ & $<\mathrm{M}$ & $\mathrm{M}$ & $15+[1]+(4)=20$ \\
\hline $\begin{array}{c}\text { Sum of values } \\
\text { more than H (for }\end{array}$ & 8 & 0 & $1+(1)$ & {$[1]+(3)$} & 6 & \\
\hline$y$ ) & & & & & \\
\hline
\end{tabular}

Note. All signs in the table 4 and table 5 are measured in a direct scale. In round brackets are given the number of values $>\mathrm{H}$ (between $\mathrm{H}$ and $\mathrm{H}$ $\mathrm{VH})$; in the square - the number of values equals $(\mathrm{H}-$ $\mathrm{VH}$ ); without brackets - the number of values $\mathrm{VH}$. Analysis of connectivity is performed separately for objects of class $X$ and class $Y$. In the analysis only the values more than $H$ are taken into account. The results of the analysis for the complex of objects $X$ are given in the table 6 . The first structural vector has the form $Q_{X}=\left(\begin{array}{lll}1 & 2 & 2\end{array}\right)$. We calculate the vector of obstacles, showing the possibility of exchange of information (signs) between the components of the complex at each level of connectivity using the ratio $D_{X}=Q_{X}-\mathrm{I}$, where I is a unit vector. We have for our case $D_{X}=\left(\begin{array}{lll}0 & 1 & 1\end{array}\right)$. We calculate the eccentricity. For $x_{9}$ and $x_{5}$ it is equal to 1 , and for the rest of simplexes is equal to 0 . Similarly the analysis of the connectivity of the complex of signs on objects of class $X$ is performed. The results are presented in table 7 .

Table 6 Analysis of objects of class X for the second case

\begin{tabular}{|c|c|c|}
\hline Level of connectivity & Number of components & Structure of components \\
\hline$q=2$ & $Q_{2}=1$ & $\left\{x_{9}\right\}$ \\
\hline$q=1$ & $Q_{1}=2$ & $\left\{x_{9}, x_{3}\right\},\left\{x_{5}\right\}$ \\
\hline$q=0$ & $Q_{0}=2$ & $\left\{x_{9}, x_{3}, x_{2}, x_{4}, x_{5}, x_{8}\right\}$, \\
$\left\{x_{1}, x_{6}\right\}$ except $x_{7}, x_{10}$ & \\
\hline
\end{tabular}


Table 7 Analysis of signs on objects of class X for the second case

\begin{tabular}{|c|c|c|}
\hline Level of connectivity & Number of components & Structure of components \\
\hline$q=4$ & $Q_{4}=1$ & $\left\{K_{1}\right\}$ \\
\hline$q=3$ & $Q_{3}=1$ & $\left\{K_{1}\right\}$ \\
\hline$q=2$ & $Q_{2}=2$ & $\left\{K_{1}\right\},\left\{K_{2}\right\}$ \\
\hline$q=1$ & $Q_{1}=4$ & $\left\{K_{1}\right\},\left\{K_{2}\right\},\left\{K_{5}\right\},\left\{K_{4}\right\}$ \\
\hline$q=0$ & $Q_{0}=2$ & $\left\{K_{1}, K_{4}, K_{5}\right\},\left\{K_{2}\right\}$ except $K_{3}$ \\
\hline
\end{tabular}

For complex of signs the first structural vector $Q_{K}(X)=\left(\begin{array}{llll}1 & 1 & 2 & 4\end{array}\right)$; vector of the obstacle $D_{K}$ $(X)=\left(\begin{array}{lllll}0 & 0 & 1 & 3 & 1\end{array}\right)$. Eccentricity $\varepsilon\left(K_{1}\right)=4, \varepsilon\left(K_{4}\right)=\varepsilon\left(K_{5}\right)$ $=1$, for $K_{2}$ and $K_{3}$ eccentricity is not defined. The results of the analysis of the complex $X$ show that complex is weakly connected and is composed of heterogeneous objects. The most typical representatives of the class are simplexes (objects) $x_{9}$ and $x_{5}$. At the level $q=1$ there is an obstacle in the exchange of information between component $\left\{x_{9}, x_{3}\right\}$ and component $\left\{x_{5}\right\}$, i.e., at this level they are not connected with any two signs. The analysis of complex of signs shows that the sign $K_{3}$ is not inherent in objects of class $X$, and the signs $K_{1}$ and $K_{2}$ are the most typical objects of this class. The first structural vector shows that the complex of signs for class $X$ is heterogeneous and weakly connected. There is an obstacle in the exchange of information between the components of the complex at the levels $q=2,1$ and 0 , i.e. these components are not connected, directly or indirectly, with any three, two and one objects respectively. We will analyse the connectivity of objects of class $Y$. The results of the analysis for the complex $Y$ are given in table 8 . The last line of the table is obtained, if we assume that gradations $\mathrm{H}-\mathrm{VH}$ and $>\mathrm{H}$ are approximately equal. We will take below this assumption.

Table 8 Analysis of objects of class Y for the second case

\begin{tabular}{|c|c|c|}
\hline Level of connectivity & Number of components & Structure of components \\
\hline$q=2$ & $Q_{2}=2$ & $\left\{y_{4}\right\},\left\{y_{13}\right\}$ \\
\hline$q=1$ & $Q_{1}=2$ & $\left\{y_{4}\right\},\left\{y_{13}, y_{2}\right\}$ \\
\hline$q=0$ & $Q_{0}=2$ & $\left\{y_{6}, y_{8}, y_{11}\right\}$, \\
& all other $y\}$ \\
\hline \multicolumn{2}{|c|}{ or } \\
\hline$q=0$ & $Q_{0}=1$ & $\{$ all $y\}$ \\
\hline
\end{tabular}

The first structural vector of complex $Q_{Y}=$ (2 221 ); vector of obstacles $D_{Y}=\left(\begin{array}{lll}1 & 1 & 0\end{array}\right)$. The eccentricity for $y_{4}$ is equal to 2 , for $y_{13}$ is 1 , and for the other $y$ is 0 . We will analyse the connectivity of the complex of signs on objects of class $Y$. The results are presented in table 9 . The last line of the table is obtained, if we assume, as above, that gradations $\mathrm{H}-\mathrm{VH}$ and $>\mathrm{H}$ are approximately equal.

Table 9 Analysis of signs on objects of class Y for the second case

\begin{tabular}{|c|c|c|}
\hline Level of connectivity & Number of components & Structure of components \\
\hline$q=7$ & $Q_{7}=1$ & $\left\{K_{1}\right\}$ \\
\hline$q=6$ & $Q_{6}=1$ & $\left\{K_{1}\right\}$ \\
\hline$q=5$ & $Q_{5}=1$ & $\left\{K_{1}\right\}$ \\
\hline$q=4$ & $Q_{4}=2$ & $\left\{K_{1}\right\},\left\{K_{5}\right\}$ \\
\hline$q=3$ & $Q_{3}=3$ & $\left\{K_{1}\right\},\left\{K_{5}\right\},\left\{K_{4}\right\}$ \\
\hline$q=2$ & $Q_{2}=3$ & $\left\{K_{1}\right\},\left\{K_{5}\right\},\left\{K_{4}\right\}$ \\
\hline$q=1$ & $Q_{1}=3$ & $\left\{K_{1}, K_{5}\right\},\left\{K_{3}\right\},\left\{K_{4}\right\}$ \\
\hline$q=0$ & $Q_{0}=2$ & $\left\{K_{1}, K_{5}, K_{3}\right\},\left\{K_{4}\right\}$ except $K_{2}$ \\
\hline \multicolumn{2}{|c|}{ or } \\
\hline$q=0$ & $Q_{0}=1$ & $\left\{K_{1}, K_{5}, K_{3}, K_{4}\right\}$ except $K_{2}$ \\
\hline
\end{tabular}

For complex of signs the first structural vector $Q_{K}(Y)=\left(\begin{array}{llllllll}1 & 1 & 1 & 2 & 3 & 3 & 3 & 1\end{array}\right)$, vector of obstacles $D_{K}(Y)=\left(\begin{array}{llllllll}0 & 0 & 0 & 1 & 2 & 2 & 2 & 0\end{array}\right)$. Eccentricity $\varepsilon\left(K_{1}\right)=6$, $\varepsilon\left(K_{4}\right)=3, \varepsilon\left(K_{2}\right)$ is not defined, $\varepsilon\left(K_{3}\right)=1, \varepsilon\left(K_{5}\right)=3$. The results of the analysis of complex $Y$ show that complex consists of heterogeneous objects and is strongly connected only at $q=0$. The most typical representatives of the class are the simplexes $y_{4}$ and $y_{13}$. There is an obstacle in the exchange of information between the components $\left\{y_{4}\right\}$ and $\left\{y_{13}\right\}$, which are not connected with any three signs, and also between $\left\{y_{4}\right\}$ and $\left\{y_{13}, y_{2}\right\}$ which are not connected directly or indirectly with any two signs. The analysis of complex of signs shows that the sign $K_{2}$ is not inherent in objects of class $Y$, and the signs $K_{1}$ and $K_{5}$ are the most typical. A comparison of the results of the analysis of signs for classes of objects $X$ and $Y$ allows to identify the most important (informative) signs. Under informativity here should understand the possibility of error-free correlation of objects to classes $X$ or $Y$. The most informative in this case are the signs $K_{2}$ and $K_{3}$, but $K_{2}$ should be preferred as it has a higher level of connectivity than $K_{3}$. (This conclusion is confirmed by the comparison 
of eccentricities). The sign $K_{1}$ follows $K_{3}$. Signs $K_{5}$ and $K_{4}$ are close in importance (informativity), but $K_{5}$ should be preferred, as it has a higher level of connectivity than $K_{4}$. Finally we have a location in descending order of importance $K_{2}>K_{3}>K_{1}>K_{5}>$ $K_{4}$.

\section{IDENTIFICATION UNCERTAIN (UNKNOWN) OBJECTS}

The third case differs from previous ones as there are three classes of objects $X, Y$ and $Z$. The objects $Z$ are of unknown nature and we have to identify them. The objects are described by several characteristics (signs). For simplicity we will use only the gradation VH and VL that does not limit the generality according to (1). The initial data are given in table 10 .

Table 10 Initial data for the third case

\begin{tabular}{|c|c|c|c|c|c|}
\hline \multirow[t]{2}{*}{ Objects } & \multicolumn{4}{|c|}{ Signs } & \multirow{2}{*}{$\begin{array}{c}\text { Sum of values } \\
\text { VH }\end{array}$} \\
\hline & $K_{1}$ & $K_{2}$ & $K_{3}$ & $K_{4}$ & \\
\hline$x_{1}$ & VL & $\mathrm{VH}$ & $\mathrm{VH}$ & $\mathrm{VL}$ & 2 \\
\hline$x_{2}$ & $\mathrm{VH}$ & VL & $\mathrm{VH}$ & $\mathrm{VH}$ & 3 \\
\hline$x_{3}$ & VL & VL & $\mathrm{VH}$ & VL & 1 \\
\hline$x_{4}$ & $\mathrm{VL}$ & VL & $\mathrm{VH}$ & $\mathrm{VH}$ & 2 \\
\hline$x_{5}$ & VL & $\mathrm{VH}$ & $\mathrm{VL}$ & $\mathrm{VH}$ & 2 \\
\hline$x_{6}$ & $\mathrm{VH}$ & VL & $\mathrm{VL}$ & $\mathrm{VH}$ & 2 \\
\hline Sum of values VH & 2 & 2 & 4 & 4 & 12 \\
\hline$y_{1}$ & VL & $\mathrm{VH}$ & $\mathrm{VL}$ & VL & 1 \\
\hline$y_{2}$ & $\mathrm{VH}$ & $\mathrm{VH}$ & $\mathrm{VL}$ & $\mathrm{VH}$ & 3 \\
\hline$y_{3}$ & VL & $\mathrm{VH}$ & $\mathrm{VH}$ & $\mathrm{VH}$ & 3 \\
\hline$y_{4}$ & $\mathrm{VH}$ & VL & $\mathrm{VH}$ & VL & 2 \\
\hline$y_{5}$ & $\mathrm{VH}$ & $\mathrm{VH}$ & $\mathrm{VH}$ & $\mathrm{VL}$ & 3 \\
\hline$y_{6}$ & $\mathrm{VH}$ & VL & VL & VL & 1 \\
\hline Sum of values VH & 4 & 4 & 3 & 2 & 13 \\
\hline$z_{1}$ & VL & VL & $\mathrm{VL}$ & $\mathrm{VH}$ & 1 \\
\hline$z_{2}$ & $\mathrm{VH}$ & $\mathrm{VH}$ & VL & VL & 2 \\
\hline$z_{3}$ & $\mathrm{VH}$ & $\mathrm{VH}$ & $\mathrm{VH}$ & $\mathrm{VH}$ & 4 \\
\hline Sum of values VH & 2 & 2 & 1 & 2 & 7 \\
\hline
\end{tabular}

To identify the objects of class $Z$ we will first conduct a separate analysis of connectivity of classes and identify informative signs, and then for more reliability of the conclusions we perform the analysis of differences $|X-Z|$ and $|Y-Z|$. Analysis of connectivity is conducted separately for classes, as in the second case. For complex of objects $X$ the results are shown in table 11 .

Table 11 Analysis of objects of class X for the third case

\begin{tabular}{|c|c|c|}
\hline Level of connectivity & Number of components & Structure of components \\
\hline$q=2$ & $Q_{2}=1$ & $\left\{x_{2}\right\}$ \\
\hline$q=1$ & $Q_{1}=3$ & $\left\{x_{2}, x_{4}, x_{6}\right\},\left\{x_{1}\right\},\left\{x_{5}\right\}$ \\
\hline$q=0$ & $Q_{0}=1$ & $\{$ all $x\}$ \\
\hline
\end{tabular}

The first structural vector $Q_{x}=\left(\begin{array}{lll}1 & 3 & 1\end{array}\right)$, the vector of obstacles $D_{X}=\left(\begin{array}{lll}0 & 2 & 0\end{array}\right)$. Eccentricity $\varepsilon\left(x_{1}\right)=\varepsilon\left(x_{5}\right)=\varepsilon\left(x_{2}\right)$ $=1, \varepsilon\left(x_{3}\right)=\varepsilon\left(x_{4}\right)=\varepsilon\left(x_{6}\right)=0$. We will analyse the connectivity of the complex of signs on objects of class $X$. The results are given in table 12 . The first structural vector $Q_{K}(X)=\left(\begin{array}{llll}2 & 2 & 2 & 1\end{array}\right)$, the vector of obstacles $D_{K}(X)=\left(\begin{array}{llll}1 & 1 & 1 & 0\end{array}\right)$. Eccentricity $\varepsilon\left(K_{3}\right)=\varepsilon\left(K_{4}\right)=$ $2, \varepsilon\left(K_{2}\right)=1, \varepsilon\left(K_{1}\right)=0$.

Table 12 Analysis of signs on objects of class X for the third case

\begin{tabular}{|c|c|c|}
\hline Level of connectivity & Number of components & Structure of components \\
\hline$q=3$ & $Q_{3}=2$ & $\left\{K_{3}\right\},\left\{K_{4}\right\}$ \\
\hline$q=2$ & $Q_{2}=2$ & $\left\{K_{3}\right\},\left\{K_{4}\right\}$ \\
\hline$q=1$ & $Q_{1}=2$ & $\left\{K_{3}, K_{4}, K_{1}\right\},\left\{K_{2}\right\}$ \\
\hline$q=0$ & $Q_{0}=1$ & $\{$ all $K\}$ \\
\hline
\end{tabular}

The results of the analysis of the complex $X$ show that it consists of heterogeneous components (objects), and when $q=1$ is weakly connected. The most typical representatives of the class are $x_{2}$ and $x_{1}$, as well as $x_{5}$. At the level $q=1$ there is an obstacle in the exchange of information between the three components of the complex, i.e. the components $\left\{x_{2}\right.$, $\left.x_{4}, x_{6}\right\},\left\{x_{1}\right\},\left\{x_{5}\right\}$ is not connected directly or indirectly with any two signs. The analysis of signs shows that the signs $K_{3}, K_{4}$ are the most typical; they are also most informative for objects of class $X$. For objects of class $Y$ the results of the analysis are given 
in table 13. The first structural vector $Q_{Y}=\left(\begin{array}{lll}3 & 1 & 1\end{array}\right)$,

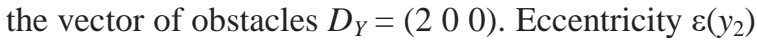
$=\varepsilon\left(y_{3}\right)=\varepsilon\left(y_{5}\right)=1, \varepsilon\left(y_{1}\right)=\mathrm{e}\left(y_{4}\right)=\varepsilon\left(y_{6}\right)=0$. For a complex of signs on objects of class $Y$ the results are presented in table 14 .

Table 13 Analysis of objects of class Y for the third case

\begin{tabular}{|c|c|c|}
\hline Level of connectivity & Number of components & Structure of components \\
\hline$q=2$ & $Q_{2}=3$ & $\left\{y_{2}\right\},\left\{y_{3}\right\},\left\{y_{5}\right\}$ \\
\hline$q=1$ & $Q_{1}=1$ & $\left\{y_{2}, y_{3}, y_{5}, y_{4}\right\}$ \\
\hline$q=0$ & $Q_{0}=1$ & $\{$ all $y\}$ \\
\hline
\end{tabular}

Table 14 Analysis of signs on objects of class Y for the third case

\begin{tabular}{|c|c|c|}
\hline Level of connectivity & Number of components & Structure of components \\
\hline$q=3$ & $Q_{3}=2$ & $\left\{K_{1}\right\},\left\{K_{2}\right\}$ \\
\hline$q=2$ & $Q_{2}=3$ & $\left\{K_{1}\right\},\left\{K_{2}\right\},\left\{K_{3}\right\}$ \\
\hline$q=1$ & $Q_{1}=1$ & $\{$ all $K\}$ \\
\hline$q=0$ & $Q_{0}=1$ & $\{$ all $K\}$ \\
\hline
\end{tabular}

The first structural vector $Q_{K}(Y)=\left(\begin{array}{llll}2 & 3 & 1 & 1\end{array}\right)$,

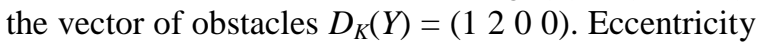
$\varepsilon\left(K_{1}\right)=\varepsilon\left(K_{2}\right)=2, \varepsilon\left(K_{3}\right)=1, \varepsilon\left(K_{4}\right)=0$. The results of the analysis of complex $Y$ show that it is, although it contains heterogeneous components, more homogeneous than the complex $X$, as $Y$ is strongly connected at $q=1$ and $q=0$. The most typical representatives of the class are $y_{2}, y_{3}, y_{5}$. These simplexes at the level $q=2$ are not connected directly or indirectly with any three characteristics (signs).
The analysis of signs shows that the signs $K_{1}, K_{2}$ are the most typical for objects of class $Y$; they are also the most informative. The comparison of the results of analysis of signs for classes of objects $X$ and $Y$ allows to identify the most important (informative) characteristics. Informativity of signs decreases in row $K_{3}, K_{2}, K_{1}=K_{4}$. For identification we should use all the signs. Let's analyse the objects of class $Z$. The results of the analysis for objects and signs are given in the tables 15 and 16.

Table 15 Analysis of objects of class $\mathrm{Z}$ for the third case

\begin{tabular}{|c|c|c|}
\hline Level of connectivity & Number of components & Structure of components \\
\hline$q=3$ & $Q_{3}=1$ & $\left\{z_{3}\right\}$ \\
\hline$q=2$ & $Q_{2}=1$ & $\left\{z_{3}\right\}$ \\
\hline$q=1$ & $Q_{1}=1$ & $\left\{z_{3}, z_{2}\right\}$ \\
\hline$q=0$ & $Q_{0}=1$ & $\{$ all $z\}$ \\
\hline
\end{tabular}

Table 16 Analysis of signs on objects of class Z for the third case

\begin{tabular}{|c|c|c|}
\hline Level of connectivity & Number of components & Structure of components \\
\hline$q=1$ & $Q_{1}=2$ & $\left\{K_{1}, K_{2}\right\},\left\{K_{4}\right\}$ \\
\hline$q=0$ & $Q_{0}=1$ & $\{$ all $K\}$ \\
\hline
\end{tabular}

The first structural vector $Q_{K}(Z)=\left(\begin{array}{ll}2 & 1\end{array}\right)$ vector of obstacles $D_{K}(Z)=(10)$. Eccentricity $\varepsilon\left(K_{1}\right)=$ $\varepsilon\left(K_{2}\right)=\varepsilon\left(K_{3}\right)=0, \varepsilon\left(K_{4}\right)=1$. The results show that the complex $Z$ contains as objects of class $X$ and class $Y$; $z_{3}$ and $z_{2}$ belong to the same class, as at $q=1$ they are combined into one component, and $z_{1}$ belong to another class. This can be seen, consistently reducing class $Z$, i.e., excluding $z_{3}$, then $z_{2}$. The belonging of objects to classes is confirmed by the results of the analysis of signs. So simplex $z_{2}$ has value $\mathrm{VH}$ at the signs $K_{1}$ and $K_{2}$, and these signs characterize the class $Y$. The simplex $z_{3}$ has a value $\mathrm{VH}$ at all signs, but belongs, as we explained above, to the same class as $z_{2}$, i.e. to class $Y$. Simplex $z_{1}$ has a value $\mathrm{VH}$ at $K_{4}$, and this sign is typical for the class $X$. For more reliability of the conclusions we will analyse the connectivity of complexes of differences $\Delta=|X-Z|$ and $\delta=|Y-Z|$ to determine the degree of closeness of objects of class $Z$ to classes $X$ and $Y$. The initial data for $\Delta$ are given in table 17 . They are obtained from the table 10 and characterize the degree of closeness $\alpha_{i j}$ of the corresponding objects. In the tables 17-20 $\Delta_{i}^{j}=\left|x_{i}-z_{j}\right|$, $\Delta^{1}=\left|x_{i}-z_{1}\right|, \Delta^{2}=\left|x_{i}-z_{2}\right|, \Delta^{3}=\left|x_{i}-z_{3}\right|$. 
Table 17 Initial data for analysis of complex $\Delta$

\begin{tabular}{|c|c|c|c|c|c|}
\hline \multirow{2}{*}{$\Delta_{i}^{j}=\left|x_{i}-z_{j}\right|$} & \multicolumn{4}{|c|}{ Signs } & \multirow[t]{2}{*}{ Sum of values VH } \\
\hline & $K_{1}$ & $K_{2}$ & $K_{3}$ & $K_{4}$ & \\
\hline$x_{1}-z_{1}$ & $\mathrm{VH}$ & VL & VL & VL & 1 \\
\hline$x_{2}-z_{1}$ & $\mathrm{VL}$ & $\mathrm{VH}$ & VL & $\mathrm{VH}$ & 2 \\
\hline$x_{3}-z_{1}$ & $\mathrm{VH}$ & $\mathrm{VH}$ & VL & $\mathrm{VL}$ & 2 \\
\hline$x_{4}-z_{1}$ & $\mathrm{VH}$ & $\mathrm{VH}$ & VL & $\mathrm{VH}$ & 3 \\
\hline$x_{5}-z_{1}$ & $\mathrm{VH}$ & VL & $\mathrm{VH}$ & $\mathrm{VH}$ & 3 \\
\hline$x_{6}-z_{1}$ & VL & $\mathrm{VH}$ & $\mathrm{VH}$ & $\mathrm{VH}$ & 3 \\
\hline Sum of values VH & 4 & 4 & 2 & 4 & 14 \\
\hline$x_{1}-z_{2}$ & $\overline{\mathrm{VL}}$ & $\overline{\mathrm{VH}}$ & VL & $\mathrm{VH}$ & 2 \\
\hline$x_{2}-z_{2}$ & $\mathrm{VH}$ & $\mathrm{VL}$ & VL & VL & 1 \\
\hline$x_{3}-z_{2}$ & $\mathrm{VL}$ & $\mathrm{VL}$ & VL & $\mathrm{VH}$ & 1 \\
\hline$x_{4}-z_{2}$ & $\mathrm{VL}$ & VL & VL & $\mathrm{VL}$ & 0 \\
\hline$x_{5}-z_{2}$ & VL & $\mathrm{VH}$ & $\mathrm{VH}$ & $\mathrm{VH}$ & 3 \\
\hline$x_{6}-z_{2}$ & $\mathrm{VH}$ & $\mathrm{VL}$ & VL & $\mathrm{VH}$ & 2 \\
\hline Sum of values VH & 2 & 2 & 1 & 4 & 9 \\
\hline$x_{1}-z_{3}$ & VL & $\mathrm{VH}$ & $\mathrm{VH}$ & $\mathrm{VL}$ & 2 \\
\hline$x_{2}-z_{3}$ & $\mathrm{VH}$ & VL & $\mathrm{VH}$ & $\mathrm{VH}$ & 3 \\
\hline$x_{3}-z_{3}$ & $\mathrm{VL}$ & $\mathrm{VL}$ & $\mathrm{VH}$ & $\mathrm{VL}$ & 1 \\
\hline$x_{4}-z_{3}$ & $\overline{\mathrm{VL}}$ & $\overline{\mathrm{VL}}$ & $\mathrm{VH}$ & $\overline{\mathrm{VH}}$ & 2 \\
\hline$x_{5}-z_{3}$ & VL & $\mathrm{VH}$ & VL & $\mathrm{VH}$ & 2 \\
\hline$x_{6}-z_{3}$ & $\mathrm{VH}$ & $\mathrm{VL}$ & VL & $\mathrm{VH}$ & 2 \\
\hline Sum of values VH & 2 & 2 & 4 & 4 & 12 \\
\hline
\end{tabular}

The results of analysis for $\Delta^{1}$ are presented in table 18 , for $\Delta^{2}-$ in table 19 , for $\Delta^{3}-$ in table 20 .

Table 18 Analysis of $\Delta^{1}$

\begin{tabular}{|c|c|c|}
\hline Level of connectivity & Number of components & Structure of components \\
\hline$q=2$ & $Q_{2}=3$ & $\left\{\Delta_{4}\right\},\left\{\Delta_{5}\right\},\left\{\Delta_{6}\right\}$ \\
\hline$q=1$ & $Q_{1}=1$ & $\left\{\Delta_{2}, \Delta_{3}, \Delta_{4}, \Delta_{5}, \Delta_{6}\right\}$ \\
\hline$q=0$ & $Q_{0}=1$ & $\{$ all $\Delta\}$ \\
\hline
\end{tabular}

Table 19 Analysis of $\Delta^{2}$

\begin{tabular}{|c|c|c|}
\hline Level of connectivity & Number of components & Structure of components \\
\hline$q=1$ & $Q_{1}=3$ & $\left\{\Delta_{1}\right\},\left\{\Delta_{5}\right\},\left\{\Delta_{6}\right\}$ \\
\hline$q=0$ & $Q_{0}=1$ & $\left\{\right.$ all $\Delta$ except $\left.\Delta_{4}\right\}$ \\
\hline
\end{tabular}

Table 20 Analysis of $\Delta^{3}$

\begin{tabular}{|c|c|c|}
\hline Level of connectivity & Number of components & Structure of components \\
\hline$q=2$ & $Q_{2}=1$ & $\left\{\Delta_{2}\right\}$ \\
\hline$q=1$ & $Q_{1}=3$ & $\left\{\Delta_{2}, \Delta_{4}, \Delta_{6}\right\},\left\{\Delta_{5}\right\},\left\{\Delta_{1}\right\}$ \\
\hline$q=0$ & $Q_{0}=1$ & $\{$ all $\Delta\}$ \\
\hline
\end{tabular}

We consider the complex $\delta=|Y-Z|$. Initial data are given in table 21 . They are obtained similar data for $\Delta$. In the tables $21-24 \delta_{i}^{j}=\left|y_{i}-z_{j}\right|$, $\delta^{1}=\left|y_{i}-z_{1}\right|, \delta^{2}=\left|y_{i}-z_{2}\right|, \delta^{3}=\left|y_{i}-z_{3}\right|$.

Table 21 Initial data for analysis of complex $\delta$

\begin{tabular}{|c|c|c|c|c|c|}
\hline \multirow{2}{*}{$\delta_{i}^{j}=\left|y_{i}-z_{j}\right|$} & \multicolumn{4}{|c|}{ Signs } & \multirow[t]{2}{*}{ Sum of values VH } \\
\hline & $K_{1}$ & $K_{2}$ & $K_{3}$ & $K_{4}$ & \\
\hline$y_{1}-z_{1}$ & $\mathrm{VH}$ & VL & $\mathrm{VH}$ & VL & 2 \\
\hline$y_{2}-z_{1}$ & VL & $\mathrm{VL}$ & $\mathrm{VH}$ & $\mathrm{VH}$ & 2 \\
\hline$y_{3}-z_{1}$ & $\mathrm{VH}$ & $\mathrm{VL}$ & $\mathrm{VL}$ & $\mathrm{VH}$ & 2 \\
\hline$y_{4}-z_{1}$ & $\mathrm{VL}$ & $\mathrm{VH}$ & VL & VL & 1 \\
\hline$y_{5}-z_{1}$ & $\mathrm{VL}$ & $\mathrm{VL}$ & VL & $\mathrm{VL}$ & 0 \\
\hline$y_{1}-z_{2}$ & VL & $\mathrm{VH}$ & $\mathrm{VH}$ & $\mathrm{VH}$ & 3 \\
\hline$y_{2}-z_{2}$ & $\mathrm{VH}$ & $\mathrm{VH}$ & $\mathrm{VH}$ & $\mathrm{VL}$ & 3 \\
\hline$y_{3}-z_{2}$ & $\mathrm{VL}$ & $\mathrm{VH}$ & $\mathrm{VL}$ & $\mathrm{VL}$ & 1 \\
\hline$y_{4}-z_{2}$ & $\mathrm{VH}$ & VL & VL & $\mathrm{VH}$ & 2 \\
\hline$y_{5}-z_{2}$ & $\mathrm{VH}$ & $\mathrm{VH}$ & $\mathrm{VL}$ & $\mathrm{VH}$ & 3 \\
\hline
\end{tabular}




\begin{tabular}{|c|c|c|c|c|c|}
\hline Sum of values VH & 4 & 4 & 3 & 4 & 15 \\
\hline$y_{1}-z_{3}$ & $\mathrm{VL}$ & $\mathrm{VH}$ & $\mathrm{VL}$ & VL & 1 \\
\hline$y_{2}-z_{3}$ & $\mathrm{VH}$ & $\mathrm{VH}$ & $\mathrm{VL}$ & VH & 3 \\
\hline$y_{3}-z_{3}$ & $\mathrm{VL}$ & $\mathrm{VH}$ & $\mathrm{VH}$ & VH & 3 \\
\hline$y_{4}-z_{3}$ & $\mathrm{VH}$ & $\mathrm{VL}$ & $\mathrm{VH}$ & $\mathrm{VL}$ & 2 \\
\hline$y_{5}-z_{3}$ & $\mathrm{VH}$ & $\mathrm{VH}$ & $\mathrm{VH}$ & $\mathrm{VL}$ & 3 \\
\hline$y_{6}-z_{3}$ & $\mathrm{VH}$ & $\mathrm{VL}$ & $\mathrm{VL}$ & VL & 1 \\
\hline Sum of values VH & 4 & 4 & 3 & 2 & 13 \\
\hline
\end{tabular}

The results of analysis for $\delta^{1}$ are presented in table 22 , for $\delta^{2}-$ in table 23 , for $\delta^{3}-$ in table 24 .

Table 22 Analysis of $\delta^{1}$

\begin{tabular}{|c|c|c|}
\hline Level of connectivity & Number of components & Structure of components \\
\hline$q=1$ & $Q_{1}=4$ & $\left\{\delta_{1}\right\},\left\{\delta_{2}\right\},\left\{\delta_{3}\right\},\left\{\delta_{6}\right\}$ \\
\hline$q=0$ & $Q_{0}=1$ & $\left\{\right.$ all $\delta$ except $\left.\delta_{5}\right\}$ \\
\hline
\end{tabular}

Table 23 Analysis of $\delta^{2}$

\begin{tabular}{|c|c|c|}
\hline Level of connectivity & Number of components & Structure of components \\
\hline$q=2$ & $Q_{2}=4$ & $\left\{\delta_{1}\right\},\left\{\delta_{2}\right\},\left\{\delta_{5}\right\},\left\{\delta_{6}\right\}$ \\
\hline$q=1$ & $Q_{1}=1$ & $\left\{\delta_{1}, \delta_{2}, \delta_{4}, \delta_{5}, \delta_{6}\right\}$ \\
\hline$q=0$ & $Q_{0}=1$ & $\{$ all $\delta\}$ \\
\hline
\end{tabular}

Table 24 Analysis of $\delta^{3}$

\begin{tabular}{|c|c|c|}
\hline Level of connectivity & Number of components & Structure of components \\
\hline$q=2$ & $Q_{2}=3$ & $\left\{\delta_{2}\right\},\left\{\delta_{3}\right\},\left\{\delta_{5}\right\}$ \\
\hline$q=1$ & $Q_{1}=1$ & $\left\{\delta_{2}, \delta_{3}, \delta_{4}, \delta_{5}\right\}$ \\
\hline$q=0$ & $Q_{0}=1$ & $\{$ all $\delta\}$ \\
\hline
\end{tabular}

The comparison of the results of analysis of connectivity for $\Delta^{1}$ and $\delta^{1}$, characterizing the proximity of $z_{1}$ to $X$ and $Y$ respectively, shows that at $q=1$ complex $\Delta^{1}$ has higher connectivity than $\delta^{1}$. The dimension of the first structural vector for $\Delta^{1}$ is more than for $\delta^{1}$. The sum of values VH for $\Delta^{1}$ equals 14, and for $\delta^{1}$ equals 9 . Therefore $z_{1}$ belongs to the class $X$. Comparison of the results for $\Delta^{2}$ and $\delta^{2}$, which characterize the proximity of $z_{2}$ to $X$ and $Y$ respectively, gives the opposite picture, namely, that complex $\delta^{2}$ has higher connectivity at $q=1$; the dimension of the first structural vector for $\delta^{2}$ is more than for $\Delta^{2}$. The sum of values $\mathrm{VH}$ for $\delta^{2}$ equals 15 , and for $\Delta^{2}$ equals 9 . Therefore $z_{2}$ belongs to class $Y$. The comparison of the results for $\Delta^{3}$ and $\delta^{3}$ characterizing the proximity of $z_{3}$ to $X$ and $Y$ respectively, shows that at $q=1$ complex $\delta^{3}$ has higher connectivity than $\Delta^{3}$, although the dimension of the first structural vector is the same for them (equals 3 ). The sum of values $\mathrm{VH}$ for $\delta^{3}$ equals 13 , and for $\Delta^{3}$ equals 12 . Consequently $z_{3}$ belongs to class $Y$, although this conclusion is not as obvious as for $z_{1}$ and $z_{2}$. A similar analysis was done for signs. We give a summary of the results. Comparison of the results for $K\left(\Delta^{1}\right)$ and $K\left(\delta^{1}\right)$ shows that complex $K\left(\Delta^{1}\right)$ has higher connectivity already at $q=1$; the first structural vector for $K\left(\Delta^{1}\right)$ consists of 4 components, and for $K\left(\delta^{1}\right)$ consists of 3 components. The sum of values $\mathrm{VH}$ is the same as for $\Delta^{1}$ and $\delta^{1}$ respectively. Therefore the conclusion that $z_{1}$ belongs to $X$ is confirmed. Comparison of the results for $K\left(\Delta^{2}\right)$ and $K\left(\delta^{2}\right)$ shows the opposite picture and confirms the conclusion that $z_{2}$ belongs to $Y$. The comparison of the results for $K\left(\Delta^{3}\right)$ and $K\left(\delta^{3}\right)$ shows that $K\left(\delta^{3}\right)$ has higher connectivity already at $q=1$, while the dimension of the first structural vector is the same. The sum of values $\mathrm{VH}$ is the same as for $\Delta^{3}$ and $\delta^{3}$. Therefore the conclusion that $z_{3}$ belongs to $Y$ is confirmed.

\section{CONCLUSION}

Note that the results in all three considered cases depend on the representativeness of a set of objects and attributes (signs) and the addition new elements can affect the results of the analysis. The comparison of presented results with the results obtained independently with the help of statistical methods shows their coincidence. Thus, application of topological methods (connectivity analysis) is a useful addition to the statistical methods, as it expands their field of application and allows without cumbersome calculations to determine the essentiality of the signs and to take a valid decision about belonging of objects to classes. The qualitative analysis provides additional information about the structure of classes, their homogeneity and coherence, which is necessary in the research and selection of objects and signs. Data representation in the form of fuzzy gradations increases the robustness of the results to errors in the original data, reduces the complexity of calculations. 


\section{REFERENCES}

[1]. Kuratowski K. Topology. Moscow: Mir, 1969 (in Russian).

[2]. Trends and progress in system identification. Edited by P. Eikhoff. Moscow: Mir, 1983 (in Russian).

[3]. Romanov V. N. Fuzzy models in system theory. SaintPetersburg: Publishing Company "LEMA", 2014 (in Russian). 